\title{
COVID-19 Associated Coagulopathy Is a Reversible Phenomenon - 3-Month Follow Up Reveals Normalization of Coagulation Status Associated With Complete Venous Recanalization in Patients After Severe COVID-19
}

\section{Abakar Magomedov}

Charite University Hospital Berlin: Charite Universitatsmedizin Berlin

Daniel Zickler

Charite University Hospital Berlin: Charite Universitatsmedizin Berlin

Stoyan Karaivanov

Charite University Hospital Berlin: Charite Universitatsmedizin Berlin

Annika Kurreck

Charite University Hospital Berlin: Charite Universitatsmedizin Berlin

Frédéric $\mathrm{H}$ Münch

Charite University Hospital Berlin: Charite Universitatsmedizin Berlin Julian Kamhieh-Milz

Charite University Hospital Berlin: Charite Universitatsmedizin Berlin Andreas Kahl

Charite University Hospital Berlin: Charite Universitatsmedizin Berlin Sophie K Piper

Charite University Hospital Berlin: Charite Universitatsmedizin Berlin

Kai-Uwe Eckardt

Charite University Hospital Berlin: Charite Universitatsmedizin Berlin

Thomas Dörner

Charite University Hospital Berlin: Charite Universitatsmedizin Berlin

Jan Matthias Kruse ( $\nabla$ jan-matthias.kruse@charite.de )

Charite Universitatsmedizin Berlin https://orcid.org/0000-0003-4250-8315

\section{Research}

Keywords: COVID-19, coagulopathy, hypofibrinolysis, Rotem aggregometry, systemic anticoagulation

Posted Date: January 13th, 2021 
DOl: https://doi.org/10.21203/rs.3.rs-143670/v1

License: (c) (1) This work is licensed under a Creative Commons Attribution 4.0 International License. Read Full License 


\section{Abstract}

Background: COVID 19 is associated with a hypercoagulable state and frequent thromboembolic complications. For how long this acquired abnormality lasts potentially requiring preventive measures, such as anticoagulation remains to be delineated.

Methods: We used viscoelastic rotational thrombelastometry (ROTEM) in a single center cohort of 13 critical ill patients and performed follow up examinations three months after discharge from ICU.

Results: We found clear signs of a hypercoagulable state due to severe hypofibrinolysis and a high rate of thromboembolic complications during the phase of acute illness. Three month follow up revealed a normalization of the initial coagulation abnormality together without evidence of venous thrombosis in all thirteen patients.

Conclusion: In our cohort the coagulation profile was completely normalized three months after COVID19. It thus appears reasonable that anticoagulation can be discontinued beyond this timepoint in patients with complete venous reperfusion.

\section{Background}

SARS-CoV-2 is a single stranded RNA virus belonging to the coronavirus family. It causes coronavirus disease 2019 (COVID-19) which often can take an asymptomatic course but can also result in substantial severe manifestations, such as acute respiratory failure, acute kidney failure, multiorgandysfunction and death. It has led to a global pandemic with over 1,600,000 attributable death toll to date. ${ }^{1}{ }^{2}$

While severe respiratory failure seems to be the most frequent cause of death, other complications like acute kidney injury, cardiac and neurologic involvement seem to occur more frequent than initially expected $^{3-6}$

From the beginning of the pandemic, a high incidence of thromboembolic complications was reported in patients with COVID-19 and autopsy findings confirmed a high rate of local thrombosis and embolic events in the pulmonary and systemic circulation associated with the disease $7,8,9,10,11,7,12,13$. Laboratory markers revealed hyperinflammation linked to a hypercoagulable status with markedly elevated levels of fibrinogen, d-dimers and thrombocytosis. In our intensive care units we performed viscoelastic testing and noted severely impaired fibrinolysis as a characteristic of procoagulation in COVID-19. ${ }^{14}$ In this context the term fibrinolytic shutdown has been proposed. ${ }^{15}$

These findings led to intensive discussions about the pros and cons of systemic anticoagulation, use of available drugs and intensity of systemic anticoagulation ${ }^{16-20}$. The question for how long survivors of the disease should receive subsequent anticoagulation as secondary prophylaxis is unclear so far. Long term data regarding the question whether the hypercoagulable state persists after clinical cure of the disease are currently lacking ${ }^{20}$. 
Here we present observational data of 13 critically ill patients with COVID-19 who presented at the post Intensive Care clinic of a tertiary care university hospital 3 months after discharge from ICU.

\section{Methods}

\section{Follow-Up Cohort}

Out of 41 Covid-19 patients admitted to our ICUs between March 25th and May 11th 2020, 29 patients survived. ${ }^{14}$ All of these were invited for a follow-up visit. Thirteen patients came back to the follow-up visit after 3 months.

\section{Anticoagulation}

Upon admission on the ICU, all COVID patients were treated with therapeutic anticoagulation using intermediate doses of unfractionated heparin or argatroban with a aPTT goal of 50-55 seconds. Nevertheless, nine out of thirteen patients suffered thromboembolic complications during their stay on the intensive care unit (ICU). These patients were then anticoagulated using higher doses of unfractionated heparin or argatroban with a targeted partial thromboplastin time of $60-80$ seconds, respectively. Upon transfer to rehabilition units the continuation of this therapy regimen was recommended.

\section{Coagulation tests}

After admission to our ICUs, routine viscoelastic tests were performed with citrated blood by using a ROTEM sigma point-of-care device (Tem International, Munich, Germany) $\left[{ }^{21}\right]$. In each patient, intrinsically (contact activation, INTEM) and extrinsically (tissue factor activation, EXTEM) activated test assays were performed to analyze the clot dynamics in both coagulation pathways. Furthermore, FIBTEM and HEPTEM were performed. For FIBTEM thrombocytes are inactivated with Cytochalasin $D$ to allow isolated evaluation of fibrinogen in clot firmness. For HEPTEM heparinase is added. The heparin effect was determined by comparing the clotting time of the INTEM with the clotting time of the HEPTEM.

The following ROTEM variables were analyzed: clotting time defined as the time until initiation of clotting; clot formation time (seconds until a clot strength reaches 20 millimeter), reflecting the kinetics of clot formation; maximum clot firmness (MCF) defined as the maximum amplitude of clot firmness; maximum lysis (ML) in percent (\%) defined as the difference between MCF and the lowest clot amplitude after MCF, reflecting fibrinolytic activity (Fig. 1).

Additional routine laboratory tests carried out according to standardized protocols comprised haemoglobin concentration, white blood cell count, platelet count, prothrombin time (PT), International Normalized Ratio (INR), activated partial thromboplastin time (aPTT), d-dimers, fibrinogen, Interleukin 6, CRP and Ferritin (see Table 2). 
Table 1

Baseline characteristics of patients with COVID-19 infection

\begin{tabular}{|c|c|c|c|c|c|c|c|}
\hline \multirow[b]{2}{*}{$\begin{array}{l}\text { Age (years, (median, } \\
[\mathrm{IQR}]))\end{array}$} & \multicolumn{2}{|c|}{$\begin{array}{l}\text { Whole Cohort } \\
(n=41)\end{array}$} & \multicolumn{2}{|c|}{$\begin{array}{l}\text { No Follow-Up- } \\
\text { Cohort }(n=28)\end{array}$} & \multicolumn{2}{|c|}{$\begin{array}{l}\text { Follow-Up } \\
\text { Cohort }(n=13)\end{array}$} & \multirow{2}{*}{$\begin{array}{l}\text { P Follow-Up } \\
\text { vs. No follow- } \\
\text { up } \\
0.019\end{array}$} \\
\hline & 67 & $\begin{array}{l}{[56.5-} \\
76.5]\end{array}$ & 69.5 & [59-78] & 60 & $\begin{array}{l}{[53-} \\
66.5]\end{array}$ & \\
\hline Gender, male $(n, \%)$ & 35 & $85.4 \%$ & 26 & $92.9 \%$ & 9 & $69.2 \%$ & ns \\
\hline $\begin{array}{l}\mathrm{BMI}, \mathrm{kg} / \mathrm{m} 2 \text { (median, } \\
{[\text { [QQR]) }}\end{array}$ & 28.0 & $\begin{array}{l}{[25-} \\
32.7]\end{array}$ & 27.8 & $\begin{array}{l}{[24.3-} \\
31.1]\end{array}$ & 29.6 & $\begin{array}{l}{[27.8-} \\
33.5]\end{array}$ & ns \\
\hline $\begin{array}{l}\text { Duration of ICU stay, days } \\
\text { (median, [IQR]) }\end{array}$ & 39.0 & $\begin{array}{l}{[24-} \\
52.5]\end{array}$ & 28.5 & $\begin{array}{l}{[24-} \\
47.5]\end{array}$ & 46 & $\begin{array}{l}{[30-} \\
62]\end{array}$ & ns \\
\hline $\begin{array}{l}\text { Death during ICU stay (n, } \\
\%)\end{array}$ & 11 & $26.8 \%$ & 11 & $39.3 \%$ & & & \\
\hline $\begin{array}{l}\text { Thromboembolic events } \\
(n, \%)\end{array}$ & 24 & $58.5 \%$ & 15 & $53.6 \%$ & 9 & $69.2 \%$ & ns \\
\hline Intubation (n, \%) & 36 & $87.8 \%$ & 25 & $89.3 \%$ & 11 & $84.6 \%$ & ns \\
\hline $\operatorname{ECMO}(n, \%)$ & 10 & $24.4 \%$ & 5 & $17.9 \%$ & 5 & $38.5 \%$ & ns \\
\hline CRRT $(n, \%)$ & 22 & $53.7 \%$ & 13 & $46.4 \%$ & 9 & $69.2 \%$ & ns \\
\hline $\begin{array}{l}\text { SOFA-Score (median, } \\
\text { [IQR]) }\end{array}$ & 9 & $\begin{array}{l}{[6.5-} \\
11.5]\end{array}$ & 8.5 & $\begin{array}{l}{[6.25-} \\
11]\end{array}$ & 10 & $\begin{array}{l}{[6.25-} \\
12.0]\end{array}$ & ns \\
\hline SIC-Score (median, [IQR]) & 3 & {$[2-4]$} & 3 & {$[2-4]$} & 3 & {$[2-4]$} & ns \\
\hline $\begin{array}{l}\text { APACHE-Score (median, } \\
\text { [IQR]) }\end{array}$ & 28 & [22-33] & 26 & [22-32] & 31.0 & $\begin{array}{l}{[25.5-} \\
34]\end{array}$ & ns \\
\hline Follow up days & & & & & 100 & $\begin{array}{l}{[63.5-} \\
108.50]\end{array}$ & \\
\hline \multicolumn{8}{|l|}{ Preexisting conditions } \\
\hline $\begin{array}{l}\text { Coronary artery disease } \\
(n, \%)\end{array}$ & 9 & $22 \%$ & 7 & $25 \%$ & 2 & $15.4 \%$ & ns \\
\hline Hypertension (n, \%) & 28 & $68.3 \%$ & 18 & $64.3 \%$ & 10 & $76.9 \%$ & ns \\
\hline $\begin{array}{l}\text { Diabetes mellitus / insulin } \\
\text { resistance }(\mathrm{n}, \%)\end{array}$ & 13 & $31.7 \%$ & 8 & 28.6 & 5 & $38.5 \%$ & ns \\
\hline $\begin{array}{l}\text { Chronic kidney disease (n, } \\
\%)\end{array}$ & 7 & $17.1 \%$ & 5 & $17.9 \%$ & 2 & $15.4 \%$ & ns \\
\hline
\end{tabular}

ECMO, Extracorporeal Membrane Oxygenation; SOFA, Sequential Organ Failure Assessment; CRRT, Continuous Renal Replacement Therapy; SIC Sepsis-Induced Coagulopathy Score; APACHE, Acute Physiology And Chronic Health Evaluation. 


\begin{tabular}{|c|c|c|c|c|c|c|c|}
\hline \multirow[b]{2}{*}{ Chronic dialysis (n, \%) } & \multicolumn{2}{|c|}{$\begin{array}{l}\text { Whole Cohort } \\
(n=41)\end{array}$} & \multicolumn{2}{|c|}{$\begin{array}{l}\text { No Follow-Up- } \\
\text { Cohort }(n=28)\end{array}$} & \multicolumn{2}{|c|}{$\begin{array}{l}\text { Follow-Up } \\
\text { Cohort }(n=13)\end{array}$} & \multirow{2}{*}{$\begin{array}{l}\text { P Follow-Up } \\
\text { vs. No follow- } \\
\text { up } \\
\text { ns }\end{array}$} \\
\hline & 1 & $2.4 \%$ & 1 & $3.6 \%$ & 0 & $0 \%$ & \\
\hline Lung disease $(n, \%)$ & 10 & $24.4 \%$ & 7 & $25 \%$ & 3 & $23.1 \%$ & ns \\
\hline
\end{tabular}

Table 2: The laboratory and ROTEM values at ICU presentation and 3 months follow-up 


\begin{tabular}{|c|c|c|c|c|c|}
\hline & & $\mathrm{ICU}(\mathrm{N}=13)$ & & w-up (N13) & \\
\hline & Median & [IQR] & Median & [IQR] & $\mathrm{p}$ value \\
\hline $\begin{array}{l}\begin{array}{l}\text { Laboratory variable } \\
\text { (normal values) }\end{array} \\
\end{array}$ & & & & & \\
\hline $\begin{array}{l}\text { Haemoglobin } \\
(12 \cdot 5-17-2 \mathrm{~g} / \mathrm{dL})\end{array}$ & $9 \cdot 9$ & {$[8 \cdot 7-11 \cdot 0]$} & $13 \cdot 6$ & {$[10 \cdot 6-14 \cdot 1]$} & 0.006 \\
\hline $\begin{array}{l}\text { White blood cells } \\
(3 \cdot 5-10-5 / \mathrm{nl})\end{array}$ & $12 \cdot 8$ & {$[8 \cdot 0-13 \cdot 6]$} & $7 \cdot 1$ & {$[5 \cdot 3-9 \cdot 1]$} & 0.023 \\
\hline $\begin{array}{c}\text { Platelet count } \\
(150-370 \mathrm{inl})\end{array}$ & $142 \cdot 0$ & {$[116 \cdot 0-271 \cdot 5]$} & $224 \cdot 0$ & {$[193 \cdot 5-237 \cdot 0]$} & 0.263 \\
\hline $\begin{array}{l}\text { Prothrombin time } \\
(70-130 \%)\end{array}$ & $79 \cdot 0$ & {$[64 \cdot 0-86 \cdot 5]$} & $85 \cdot 0$ & {$[78 \cdot 5-96 \cdot 5]$} & 0.196 \\
\hline $\begin{array}{l}\text { INR } \\
(0 \cdot 9-1 \cdot 25)\end{array}$ & $1 \cdot 2$ & {$[1 \cdot 1-1 \cdot 4]$} & $1 \cdot 1$ & {$[1 \cdot 0-1 \cdot 2]$} & 0.173 \\
\hline $\begin{array}{l}\mathrm{aPTT} \\
(26-40 \mathrm{sec})\end{array}$ & 56.4 & {$[49 \cdot 2-62 \cdot 0]$} & 36.8 & {$\left[\begin{array}{lll}34 \cdot 4 & -43 \cdot 7]\end{array}\right.$} & 0.033 \\
\hline $\begin{array}{l}\text { D-dimers } \\
(<0.5 \mathrm{mg} / \mathrm{l})\end{array}$ & $4 \cdot 8$ & {$[3 \cdot 9-7 \cdot 8]$} & 0.4 & {$[0.3-0.8]$} & 0.001 \\
\hline $\begin{array}{l}\text { Fibrinogen } \\
(1 \cdot 6-4 \mathrm{~g} / 1)\end{array}$ & $6 \cdot 7$ & {$\left[\begin{array}{lll}4 \cdot 7 & -8 \cdot 3\end{array}\right]$} & $3 \cdot 6$ & {$[2 \cdot 9-4 \cdot 5]$} & 0.006 \\
\hline $\begin{array}{l}\text { IL-6 } \\
(<7 \mathrm{ng} / \mathrm{l})\end{array}$ & $173 \cdot 0$ & {$[68 \cdot 0-358 \cdot 0]$} & $2 \cdot 9$ & {$[2 \cdot 1-6 \cdot 3]$} & 0.002 \\
\hline $\begin{array}{l}\mathrm{CRP} \\
(<0.5 \mathrm{mg} / \mathrm{l})\end{array}$ & $191 \cdot 0$ & {$[121 \cdot 0-314 \cdot 4]$} & $3 \cdot 0$ & {$[1.6-5 \cdot 4]$} & 0.001 \\
\hline $\begin{array}{l}\text { Ferritin } \\
(30-400 \mu \mathrm{g} / \mathrm{l})\end{array}$ & $2408 \cdot 7$ & {$[1441-5-5280 \cdot 5]$} & $190-4$ & {$[108 \cdot 6-288 \cdot 2]$} & 0.002 \\
\hline ROTEM variables & & & & & \\
\hline FIBTEM CT (sec) & $92 \cdot 0$ & {$[86.5-104 \cdot 5]$} & $99 \cdot 0$ & {$[68.0-110 \cdot 5]$} & 0.463 \\
\hline FIBTEM CFT (sec) & $101 \cdot 0$ & {$[54 \cdot 5-200 \cdot 5]$} & $198 \cdot 0$ & {$[57.5-559.0]$} & 0.225 \\
\hline FIBTEM A10 (mm) & $29 \cdot 0$ & {$[24 \cdot 0-35 \cdot 5]$} & $15 \cdot 0$ & {$[13 \cdot 0-21.5]$} & 0.002 \\
\hline FIBTEMMCF (mm) & $32 \cdot 0$ & {$[27 \cdot 0-39 \cdot 0]$} & $16 \cdot 0$ & {$[14 \cdot 0-24 \cdot 0]$} & 0.002 \\
\hline EXTEM CT (sec) & $88 \cdot 0$ & {$[83 \cdot 5-101 \cdot 0]$} & $79 \cdot 0$ & {$[62 \cdot 5-100 \cdot 5]$} & 0.039 \\
\hline EXTEM CFT (sec) & $54 \cdot 0$ & {$\left[\begin{array}{lll}42-0 & -64 \cdot 5]\end{array}\right.$} & $64 \cdot 0$ & {$[48 \cdot 5-82 \cdot 5]$} & 0.208 \\
\hline EXTEM A10 (mm) & $66 \cdot 0$ & {$[63.0-68.5]$} & $59 \cdot 0$ & {$[54 \cdot 5-62 \cdot 5]$} & 0.033 \\
\hline EXTEMMCF $(\mathrm{mm})$ & $73 \cdot 0$ & {$[71-5-76 \cdot 0]$} & $66 \cdot 0$ & {$[63 \cdot 5-70 \cdot 0]$} & 0.004 \\
\hline INTEM CT (sec) & $215 \cdot 0$ & {$[187-5-258 \cdot 0]$} & $189 \cdot 0$ & {$[176 \cdot 5-201 \cdot 5]$} & 0.019 \\
\hline INTEM CFT (sec) & $56 \cdot 0$ & {$[50-5-60 \cdot 5]$} & $71 \cdot 0$ & {$\left[\begin{array}{lll}52 \cdot 5 & -79 \cdot 5]\end{array}\right.$} & 0.075 \\
\hline INTEM A10 (mm) & $64 \cdot 0$ & {$[60-0-70 \cdot 5]$} & $57 \cdot 0$ & {$[53 \cdot 5-59 \cdot 5]$} & 0.006 \\
\hline INTEMMCF (mm) & $73 \cdot 0$ & {$[70-0-76 \cdot 5]$} & $63 \cdot 0$ & {$[59 \cdot 5-67 \cdot 5]$} & 0.003 \\
\hline ML EXTEM (\%) & $3 \cdot 0$ & {$\left[\begin{array}{lll}3 \cdot 0 & -5 \cdot 0]\end{array}\right.$} & $8 \cdot 0$ & {$[6.0-12.0]$} & 0.002 \\
\hline ML INTEM (\%) & $2 \cdot 0$ & {$[2 \cdot 0-4 \cdot 0]$} & $8 \cdot 0$ & {$[6 \cdot 0-13 \cdot 0]$} & 0.002 \\
\hline
\end{tabular}

Unless values are designated as maximum values during the ICU stay, these parameters were determined on the day, when ROTEM analysis was performed, after admission to our ICUs. CT: Clotting Time; CFT: Clot Formation Time; MCF: Maximum Clot Firmness; ML: Maximum Lysis

\section{Ultrasound assessments}

During the ICU stay we performed ultrasound examinations in all patients (GE Vivid S70 ultrasound machine with a 9L-D probe) to screen for deep venous thrombosis, focusing on the jugular, subclavian, brachial, femoral and popliteal veins upon admission to our ICU and subsequently at least once a week. 
The same examinations were performed as part of the 3 months follow-up visit.

\section{Post-ICU-Follow-up evaluations}

All patients were invited for follow-up visits scheduled 3 months after discharge from the ICU. Follow-up visits took place at our post-ICU outpatient department and followed a standardized procedure including a medical consultation, ultrasound examination of the large vessels as described above and routine laboratory work up, including vioscoelastic tests.

\section{Ethics}

The study was approved by the ethics committees of Charité - Universitätsmedizin Berlin (EA4/115/20).

\section{Statistics}

Statistical evaluations were performed with IBM® SPSS ${ }^{\circledR}$ Statistics Version 26 (New York, USA) and GraphPad Prism (version 8.4.3; GraphPad Software, San Diego, CA, USA). Descriptive variables were given as median with limits of the interquartile range (IQR) for continuous variables or as absolute and relative frequencies for categorical variables.

Continuous data were mostly right skewed. Therefore, Wilcoxon signed rank test was used to compare changes in continuous variables between ICU stay and 3 months follow-up evaluation. A two-sided significance level of 0.05 was applied without adjustment for multiple comparison. All p-values constitute exploratory data analyses and do not allow for confirmatory generalization of results.

\section{Results}

Out of 41 Covid-19 patients admitted to our ICUs between March 25th and May 11th 2020, thirteen patients came back to the follow-up visit after three months. Nine of these were male with a median age of 60 [IQR 53-67] years and a median BMI of 29.6 [IQR 27.8-33.9].

Their median SOFA score was 10.0 [IQR 5.3-11.8] points and their median APACHE II was 32.5 [IQR 25.3-34.0] points. Eleven patients required mechanical ventilation, whereas extracorporeal membrane oxygenation was required in five (38.5\%). Nine patients developed acute renal failure requiring continuous renal replacement therapy. Median length of stay in the intensive care unit was 45 [IQR 30-65] days.

During ICU stay, nine patients developed thromboembolic complications. In this regard, two patients developed pulmonary embolisms, while lower-extremity deep venous thrombosis was found in seven patients.

At 3 month follow-up, there was no sonographic evidence of thrombosis in any of the patients indicating complete recanalization of the prior occluded veins. (see Table 3 ) 


\begin{tabular}{|llll|}
\hline Age & Gender & Thromboembolic event & follow-up sonogram \\
\hline 51 & F & left femoral vein & no evidence of thrombosis \\
\hline 59 & M & left femoral vein & no evidence of thrombosis \\
\hline 60 & M & left popliteal vein & no evidence of thrombosis \\
\hline 67 & M & left and right popliteal vein & no evidence of thrombosis \\
\hline 64 & F & bilateral central pulmonary embolism & no evidence of thrombosis \\
\hline 56 & M & right femoral and external iliac vein & no evidence of thrombosis \\
\hline 47 & M & bilateral central pulmonary embolism & no evidence of thrombosis \\
\hline 38 & F & femoral vein and ecmo cannula clotting & no evidence of thrombosis \\
\hline 75 & M & right internal jugular vein & no evidence of thrombosis \\
\hline 68 & M & no thromboembolic event & no evidence of thrombosis \\
\hline 62 & M & no thromboembolic event & no evidence of thrombosis \\
\hline 55 & F & no thromboembolic event & no evidence of thrombosis \\
\hline 66 & M & no thromboembolic event & no evidence of thrombosis \\
\hline
\end{tabular}

\section{Laboratory parameters}

The laboratory values are displayed in Table 2 and showed distinctive changes between the ICU and postdischarge timepoints regarding inflammatory and coagulation parameters.

In terms of the measurements of coagulation values, patients on ICU had significantly elevated levels of d-dimers (4.8 mg/I [IQR 3.9-7.8] vs. $0.4 \mathrm{mg} / \mathrm{I}$ [IQR 0.3-0.8], $\mathrm{p}=0.001)$ and fibrinogen (6.7 mg/I [IQR 4.78.3] vs. $3.6 \mathrm{mg} / \mathrm{I}$ [IQR 2.9-4.5], $\mathrm{p}=0.006$ ) compared to their follow-up measurements. Moreover, the median of fibrinogen and d-dimers levels returned to a normal level at the follow-up visit. aPTT was significantly prolonged during the ICU stay (56.4 sec [IQR 47.6-62.0] vs. $36.8 \mathrm{sec}$ [IQR 34.4-43.7], $\mathrm{p}=$ 0.033), whereas prothrombin time and INR revealed no significant difference between measurement time points. CRP (191.0 mg/I [IQR 121.0-314.4] vs. $2.9 \mathrm{mg} / \mathrm{I}$ [IQR 2.1-6.3], p=0.001), Ferritin (2408.7 $\mu \mathrm{g} / \mathrm{l}$ [IQR1441.5-5280.5] vs. 190.4 $\mu \mathrm{g} / \mathrm{I}$ [IQR 108.6-288.2], $\mathrm{p}=0.002)$ and IL-6 (177 ng/I [IQR $68.0-358.0]$ vs. $2.9 \mathrm{ng} / \mathrm{I}[\mathrm{IQR} 2.1-6.3], \mathrm{p}=0.02$ ) were significantly elevated during the ICU stay.

Notably, ROTEM analyses showed substantial changes between the measurements between the ICU stay and follow-up visit. Maximum clot firmness decreased significantly with median values from $73 \mathrm{~mm}$ [IQR 70.0-76.5] to $63.0 \mathrm{~mm}$ [IQR 59.5-67.5] ( $\mathrm{p}=0.003$ ), in INTEM; from $73 \mathrm{~mm}$ [IQR 71.5-76] to $66.0 \mathrm{~mm}$ [IQR 
63.5-70.0] $(p=0.004)$ in EXTEM and from $32 \mathrm{~mm}$ [IQR 27.0-39] to $16 \mathrm{~mm}$ [IQR 14-24] $(p=0.002)$, in FIBTEM.

Clot formation time in EXTEM und INTEM were longer at the follow up visit compared to ICU measurements, but these changes were not statistically significant. In contrast to the ICU values, the maximum Lysis (ML) in INTEM and EXTEM increased significantly until 3 months follow-up (ML INTEM from 2\% [IQR 2-4] to 8\% [IQR 6-13] at Follow-Up; $p=0.002$; ML EXTEM median from 3\% [IQR 3-5] to 8\% [IQR 6-12] at Follow-Up; $p=0.002$ ) marking a substantial normalization of the fibrinolytic capacity which was markedly impaired at the initial assessments.

\section{Discussion}

We report the data of thirteen critically ill patients with COVID-19, who initially required ICU admission with a severely hyperinflammatory and hypercoagulable state characterized by high levels of d-dimers and fibrinogen and a markedly increased clot firmness consistent with impaired fibrionolysis. While a hypercoagulable state was noted during their stay on the ICU, on their first visit in the ICU-follow-up clinic three months after discharge, they presented with normalized markers of inflammation and coagulation. Fibrinolytic activity and clot firmness had returned to normal values consistent with the reversible nature of the initial hypofibrinolysis. All patients analyzed showed normal d-dimer levels reflecting normalized turnover of the coagulation system also taken as surrogate of recurrence risks. Following normalization of laboratory values and viscoelastic parameters anticoagulation has been discontinued in all patients.

Venous and arterial thormbembolism contribute significantly to morbidity and mortality in COVID-197,8,9, $10,11,7,12,13$. The nature of COVID-19 coagulopathy appears to be complex and the exact mechanisms still have to be elucidated. In contrast to septic coagulopathy thrombocytopenia seems to be a rare finding and only few patients with COVID-19 meet the criteria for disseminated intravascular coagulation 22

Ranucci and Panagida performed comprehensive coagulation analyses in critical ill patients with COVID19 including viscoelastic testing and demonstrated increased clot firmness beside significant elevations in levels of $d$-dimers and fibrinogen-levels as reported by various other authors ${ }^{23-2525}$. The amplitude of the d-dimer level was associated with increased mortality in several studies ${ }^{26},{ }^{25}$. Spiezia et al. and Pavoni et al. have also recently shown severe hypercoagulopathy in critical-ill COVID-19 patients using viscoelastic testing. ${ }^{27,28}$ Microthrombus formation in the lungs and various other organs has been described in autopsy series ${ }^{11,29}$ Microvascular injury associated with complement deposition might serve as a possible explanation as Magro et al reported in their study ${ }^{30}$.

SARS-CoV2 can infect endothelial cells through the ACE2-receptor and cause endothelial damage and apoptosis ${ }^{31}$. Endothelial injury resulting in substantial endothelitis together with dysfunction seems to play a crucial role in the induction of microvascular thrombosis in COVID-19 32 
Panagida et al found diminished activity of fibrinolysis in their ROTEM-analysis. ${ }^{23}$ Similar changes have been reported in septic patients and might indicate protective mechanisms employed to isolate intruding pathogens ${ }^{33} 34$. One might interpret the persisiting fibrinolytic shutdown in COVID-19 as a consequence of the fact that there is no effective therapeutic agent to influence viremia until today and to protect the endothelial cells that are not only the target of SARS-Cov2 but also the key tissue regulating fibrinolysis. Impaired fibrinolysis has also been linked to the pathogenesis of ARDS in general ${ }^{35} 36$

Continuosly reported high levels of inflammatory cytokines and infiltration of tissues with granuloctes and monocytes as demonstrated for lung tissue in autopsy using caspase-3 immunostaining probably also play an important role in the pathogenesis of coagulopathy and thrombophilia in COVID-19 3237 with a particular impact on endothelial damage.

Tang et al demonstrated decreased mortality in COVID-19 patients with coagulopathy who were treated with unfractionated heparin compared to those who did not receive heparin ${ }^{38}$ Heparin has antiinflammatory effects and might mitigate capillary leakage and favorably influence the toxic effect of damage associated molecular patterns (DAMPS) and histones on the endothelium ${ }^{39} 40$.

The American College of chest physicians (ACCP) and the American Society of hematology (ASH) recommended low molecular weight heparin (LMWH) in prophylactic doses in critical ill COVID-19 patients and in therapeutic dose if venous thromboembolism (VTE) occurred ${ }^{16}$

Recent guidelines of the International society on thrombosis and hemostasis (ISTH) recommend either prophylactic or intermediate dosing of LMWH or UFH. ${ }^{41}$

Given the high incidence of thromboembolic events many centers switched to intermediate dosing of anticoagulation instead of standard prophylaxis ${ }^{13} 42$

As a consequence, our patients received unfractionated heparin with a target PTT of 50-55 (normal range aPTT $39 \mathrm{~s}$ ) seconds as long as there were no thromboembolic complications. Patients with thromboembolic events received therapeutic doses of unfractionated heparin with a target PTT of 60-80 seconds. Patients who showed resistance to heparin and failed to reach the target-PTT within a reasonable amount of time despite adequate dosing, were switched to Argatroban for direct thrombin inhibition.

In contrast to individual parameters, viscoelastic methods like thrombelastography and ROTEM permit functional evaluations of whole blood aggregometry. Thus it allows evaluation of the different and complex coagulation phases including the initiation, formation and stabilization of a clot, and finally, clot lysis. Still endothelial function and the influence of soluble tissue factor have to be taken into account as they will not be represented in the results of the test. Not only bleeding diathesis as the classical indication for viscoelastic testing but also hypercoagulable conditions due to different diseases were 
examined in the past using ROTEM and states of hyper- and hypofibrinolysis could be reliably detected and characterized by viscoelastic tests $43,44,33,45$.

Our cohort presented with a significantly increased clot firmness on the one hand and severely impaired fibrinolytic activity represented by a maximum lysis of $<3 \%$ during their ICU-stay on the other.

The clot lysis parameter ML provides information on the fibrinolytic capacity and was successfully used in several studies to asses hyper-, or hypofibrinolysis. Lower values of ML provide evidence of existing hypofibrinolysis, while values above $15 \%$ are suggestive for hyperfibrinolysis. Nouigier et al reported in their recent study that critical ill patient with COVID pneumonia have an impaired fibrinolytic capacity which was associated with increased levels of PAI-1 and TAFI. ${ }^{46}$ It has also been proposed that decreased activity of urokinase-type plasminogen activator and increased release of plasminogen activator inhibitor-1 might be the mediating mechanism of hypofibrinolysis, but data to support this further are scarce ${ }^{47}$.

On their 12-week follow up visit, clot firmness and fibrinolytic activity had normalized in all patients. The significant increase of $\mathrm{ML}$ in the follow-up assessment indicates an appropriate regeneration or reversibility of physiologic fibrinolytic capacity.

To the best of our knowledge, this is a first study reporting follow-up data on the reversibility of coagulation abnormalities after COVID-19 infection including viscoelastic testing.

ACCP recommends to evaluate patients for extended prophylaxis after their hospital stay depending on their risk of bleeding. ${ }^{16}$ ISTH states, that post discharge prophylaxis for 2-6 weeks should be considered ${ }^{41}$. For patients after VTE, current guidelines recommend therapeutic anticoagulation for at least 3 months ${ }^{41}$

Especially patients with high d-dimer values were found to be at high risk of post-discharge VTE independent of COVID-19 ${ }^{48}$ Around $60 \%$ of all VTE in medical patients occur in the post-hospital discharge period with a more than 5 times increased risk in fatal pulmonary embolism ${ }^{49}$. Newer studies reported favorable risk-benefit ratios for extendend prophylaxis in medical patients 50

In conclusion our patients who suffered from thromboembolic events during their course of COVID-19 received therapeutic anticoagulation during their ICU stay and continuation was recommended for the first three months thereafter. Taking into account the grade of immobilization and the high levels of $d$ dimers, increased clot firmness and severely impaired fibrinolysis on viscoelastic testing, we recommended therapeutic anticoagulation in the patients without thromboembolic complications until reassesement during their first visit on the post-ICU-clinic.

On their 3 months follow-up visit all patients presented with normalized values of d-dimer, fibrinogen and viscoelastic testing. Inflammatory markers were also normalized. Since there were no signs of a persistent hypercoagulable state left and none of the patients suffered from a thromboembolic event 
after discharge we conclude that anticoagulation may be terminated no later than three months after discharge from the ICU.

Our study has several limitations. We report the data of a relatively small single center cohort of critically ill patients which may limit generalizability. Due to its retrospective nature it can only be hypothesis generating. Our presumptions have to be verified in a clinical trial focusing not only on coagulation profiles but also on clinical data such as rate of thromboembolic events and ideally survival. All patients received intermediate or full dose anticoagulation and an interaction with our laboratory and viscoelastic markers cannot be entirely excluded.

Furthermore, in the meantime between ICU discharge and follow-up, no control follow-ups were routinely performed or analyzed.

Moreover, we only performed anamnesis, clinical examination and screening ultrasound examinations as follow-up exams.. There were no clinical or anamnestic hints for pulmonary embolism but routine tests regarding asymptmomatic events were performed so no statements regarding asymptomatic pulmonary embolism can be made.

In summary, we found substantially limited fibrinolysis in acutely ill COVID-19 patients with normalization after three months.

\section{Conclusion}

In our cohort of critically ill COVID-19 patients, the coagulation profile and inflammatory markers were completely normalized three months after discharge from the ICU. It thus appears reasonable that anticoagulation can be discontinued beyond this timepoint in patients with complete venous reperfusion.

\section{Abbreviations}

ROTEM: rotational thrombelastometry

COVID-19: coronavirus 2019

SARS-CoV-2: severe acute respiratory syndrome coronavirus 2

ARDS: acute respiratory distress syndrome

ICU: intensive care units

MCF: maximum clot firmness

ML: maximum lysis

PT: prothrombin time 
INR: International Normalized Ratio

aPTT: activated partial thromboplastin time

t-PA: tissue-type plasminogen activator

PAl-1Plasminogen activator inhibitor-1

IQR: interquartile range

ROC: receiver operating characteristic

AUC: area under the curve

Cl: confidence intervals

PCT: procalcitonin

CRP: C-reactive protein

\section{Declarations}

\section{Ethics approval and consent to participate:}

The study was approved by the ethics committees of Charite - Universitätsmedizin Berlin (EA4/115/20) and was in compliance with the Declaration of Helsinki. Consent to participate was not applicable due to the retrospective nature of the study.

\section{Consenst for publication:}

Not applicable.

\section{Availability of data and material:}

The datasets analyzed during the current study are available from the corresponding author upon reasonable request.

\section{Competing interests:}

There are no competing interests to be declared by the authors.

\section{Funding:}

This research received no specific grant from any funding agency in the public, commercial, or not-forprofit sectors.

\section{Author's contribution:}


JMK, DZ, AM , SK, SP, JK-M, IG, AK, FHM, TD and KUE collected and interpreted clinical data. JMK, DZ and AM wrote the first manuscript draft, all authors revised and approved the manuscript.

\section{Acknowlegements:}

Not applicable.

\section{References}

1. Jin Y, Yang H, Ji W, et al. Virology, Epidemiology, Pathogenesis, and Control of COVID-19. Viruses 2020;12.

2. Dong E, Du H, Gardner L. An interactive web-based dashboard to track COVID-19 in real time. Lancet Infect Dis 2020;20:533-4.

3. Ronco C, Reis T, Husain-Syed F. Management of acute kidney injury in patients with COVID-19. Lancet Respir Med 2020;8:738-42.

4. Chan L, Chaudhary K, Saha A, et al. AKI in Hospitalized Patients with COVID-19. J Am Soc Nephrol 2020.

5. Akhmerov A, Marban E. COVID-19 and the Heart. Circ Res 2020;126:1443-55.

6. Mao L, Jin H, Wang M, et al. Neurologic Manifestations of Hospitalized Patients With Coronavirus Disease 2019 in Wuhan, China. JAMA Neurol 2020;77:683-90.

7. Lodigiani C, lapichino G, Carenzo L, et al. Venous and arterial thromboembolic complications in COVID-19 patients admitted to an academic hospital in Milan, Italy. Thromb Res 2020;191:9-14.

8. Helms J, Tacquard C, Severac F, et al. High risk of thrombosis in patients with severe SARS-CoV-2 infection: a multicenter prospective cohort study. Intensive Care Med 2020.

9. Klok FA, Kruip M, van der Meer NJM, et al. Incidence of thrombotic complications in critically ill ICU patients with COVID-19. Thromb Res 2020.

10. Menter T, Haslbauer JD, Nienhold R, et al. Post-mortem examination of COVID19 patients reveals diffuse alveolar damage with severe capillary congestion and variegated findings of lungs and other organs suggesting vascular dysfunction. Histopathology 2020.

11. Wichmann D, Sperhake JP, Lutgehetmann M, et al. Autopsy Findings and Venous Thromboembolism in Patients With COVID-19: A Prospective Cohort Study. Ann Intern Med 2020.

12. Llitjos JF, Leclerc $M$, Chochois $C$, et al. High incidence of venous thromboembolic events in anticoagulated severe COVID-19 patients. J Thromb Haemost 2020.

13. Middeldorp S, Coppens M, van Haaps TF, et al. Incidence of venous thromboembolism in hospitalized patients with COVID-19. J Thromb Haemost 2020;18:1995-2002.

14. Kruse JM, Magomedov A, Kurreck A, et al. Thromboembolic complications in critically ill COVID-19 patients are associated with impaired fibrinolysis. Crit Care 2020;24:676. 
15. Wright FL, Vogler TO, Moore EE, et al. Fibrinolysis Shutdown Correlation with Thromboembolic Events in Severe COVID-19 Infection. J Am Coll Surg 2020;231:193-203 e1.

16. Moores LK, Tritschler T, Brosnahan S, et al. Prevention, Diagnosis, and Treatment of VTE in Patients With Coronavirus Disease 2019: CHEST Guideline and Expert Panel Report. Chest 2020;158:1143-63.

17. McGlynn F, McGrath J, Varghese C, et al. Argatroban for therapeutic anticoagulation for heparin resistance associated with Covid-19 infection. J Thromb Thrombolysis 2020.

18. Aliter KF, Al-Horani RA. Thrombin Inhibition by Argatroban: Potential Therapeutic Benefits in COVID19. Cardiovasc Drugs Ther 2020.

19. Arachchillage DJ, Remmington C, Rosenberg A, et al. Anticoagulation with argatroban in patients with acute antithrombin deficiency in severe COVID-19. Br J Haematol 2020;190:e286-e8.

20. Barnes GD, Burnett A, Allen A, et al. Thromboembolism and anticoagulant therapy during the COVID19 pandemic: interim clinical guidance from the anticoagulation forum. $\mathrm{J}$ Thromb Thrombolysis 2020;50:72-81.

21. Gorlinger K, Bhardwaj V, Kapoor PM. Simulation in coagulation testing using rotational thromboelastometry: A fast emerging, reliable point of care technique. Ann Card Anaesth 2016;19:516-20.

22. Deng Y, Liu W, Liu K, et al. Clinical characteristics of fatal and recovered cases of coronavirus disease 2019 in Wuhan, China: a retrospective study. Chin Med J (Engl) 2020;133:1261-7.

23. Panigada M, Bottino N, Tagliabue P, et al. Hypercoagulability of COVID-19 patients in Intensive Care Unit. A Report of Thromboelastography Findings and other Parameters of Hemostasis. J Thromb Haemost 2020.

24. Ranucci M, Ballotta A, Di Dedda U, et al. The procoagulant pattern of patients with COVID-19 acute respiratory distress syndrome. J Thromb Haemost 2020;18:1747-51.

25. Zhou F, Yu T, Du R, et al. Clinical course and risk factors for mortality of adult inpatients with COVID19 in Wuhan, China: a retrospective cohort study. Lancet 2020;395:1054-62.

26. Zhang LT, Yan XS, Fan QK, et al. D-dimer levels on admission to predict in-hospital mortality in patients with Covid-19. Journal of Thrombosis and Haemostasis 2020;18:1324-9.

27. Spiezia L, Boscolo A, Poletto F, et al. COVID-19-Related Severe Hypercoagulability in Patients Admitted to Intensive Care Unit for Acute Respiratory Failure. Thromb Haemost 2020.

28. Pavoni V, Gianesello L, Pazzi M, Stera C, Meconi T, Frigieri FC. Evaluation of coagulation function by rotation thromboelastometry in critically ill patients with severe COVID-19 pneumonia. J Thromb Thrombolysis 2020:1-6.

29. Zhang Y, Cao W, Xiao M, et al. [Clinical and coagulation characteristics of 7 patients with critical COVID-2019 pneumonia and acro-ischemia]. Zhonghua Xue Ye Xue Za Zhi 2020;41:E006.

30. Magro C, Mulvey JJ, Berlin D, et al. Complement associated microvascular injury and thrombosis in the pathogenesis of severe COVID-19 infection: A report of five cases. Transl Res 2020;220:1-13. 
31. Zhang H, Penninger JM, Li Y, Zhong N, Slutsky AS. Angiotensin-converting enzyme 2 (ACE2) as a SARS-CoV-2 receptor: molecular mechanisms and potential therapeutic target. Intensive Care Med 2020;46:586-90.

32. Varga Z, Flammer AJ, Steiger P, et al. Endothelial cell infection and endotheliitis in COVID-19. Lancet 2020;395:1417-8.

33. Schmitt FCF, Manolov V, Morgenstern J, et al. Acute fibrinolysis shutdown occurs early in septic shock and is associated with increased morbidity and mortality: results of an observational pilot study. Ann Intensive Care 2019;9:19.

34. Antoniak S, Mackman N. Multiple roles of the coagulation protease cascade during virus infection. Blood 2014;123:2605-13.

35. Gunther A, Mosavi P, Heinemann S, et al. Alveolar fibrin formation caused by enhanced procoagulant and depressed fibrinolytic capacities in severe pneumonia. Comparison with the acute respiratory distress syndrome. Am J Respir Crit Care Med 2000;161:454-62.

36. Glas GJ, Van Der Sluijs KF, Schultz MJ, Hofstra JJ, Van Der Poll T, Levi M. Bronchoalveolar hemostasis in lung injury and acute respiratory distress syndrome. J Thromb Haemost 2013;11:1725.

37. Xiong Y, Liu Y, Cao L, et al. Transcriptomic characteristics of bronchoalveolar lavage fluid and peripheral blood mononuclear cells in COVID-19 patients. Emerg Microbes Infect 2020;9:761-70.

38. Tang N, Bai H, Chen X, Gong J, Li D, Sun Z. Anticoagulant treatment is associated with decreased mortality in severe coronavirus disease 2019 patients with coagulopathy. J Thromb Haemost 2020;18:1094-9.

39. Liu Y, Mu S, Li X, Liang Y, Wang L, Ma X. Unfractionated Heparin Alleviates Sepsis-Induced Acute Lung Injury by Protecting Tight Junctions. J Surg Res 2019;238:175-85.

40. Thachil J. The versatile heparin in COVID-19. J Thromb Haemost 2020;18:1020-2.

41. Spyropoulos AC, Levy JH, Ageno W, et al. Scientific and Standardization Committee communication: Clinical guidance on the diagnosis, prevention, and treatment of venous thromboembolism in hospitalized patients with COVID-19. J Thromb Haemost 2020;18:1859-65.

42. Connors JM, Levy JH. COVID-19 and its implications for thrombosis and anticoagulation. Blood 2020;135:2033-40.

43. Hincker A, Feit J, Sladen RN, Wagener G. Rotational thromboelastometry predicts thromboembolic complications after major non-cardiac surgery. Crit Care 2014;18:549.

44. Akay OM, Ustuner Z, Canturk Z, Mutlu FS, Gulbas Z. Laboratory investigation of hypercoagulability in cancer patients using rotation thrombelastography. Med Oncol 2009;26:358-64.

45. Schochl H, Frietsch T, Pavelka M, Jambor C. Hyperfibrinolysis after major trauma: differential diagnosis of lysis patterns and prognostic value of thrombelastometry. J Trauma 2009;67:125-31.

46. Nougier C, Benoit R, Simon M, et al. Hypofibrinolytic state and high thrombin generation may play a major role in SARS-COV2 associated thrombosis. J Thromb Haemost 2020. 
47. D'Alonzo D, De Fenza M, Pavone V. COVID-19 and pneumonia: a role for the uPA/uPAR system. Drug Discov Today 2020;25:1528-34.

48. Spyropoulos AC, Lipardi C, Xu J, et al. Modified IMPROVE VTE Risk Score and Elevated D-Dimer Identify a High Venous Thromboembolism Risk in Acutely III Medical Population for Extended Thromboprophylaxis. TH Open 2020;4:e59-e65.

49. Spyropoulos AC, Anderson FA, Jr., FitzGerald G, et al. Predictive and associative models to identify hospitalized medical patients at risk for VTE. Chest 2011;140:706-14.

50. Hull RD, Schellong SM, Tapson VF, et al. Extended-duration venous thromboembolism prophylaxis in acutely ill medical patients with recently reduced mobility: a randomized trial. Ann Intern Med 2010;153:8-18.

\section{Figures}



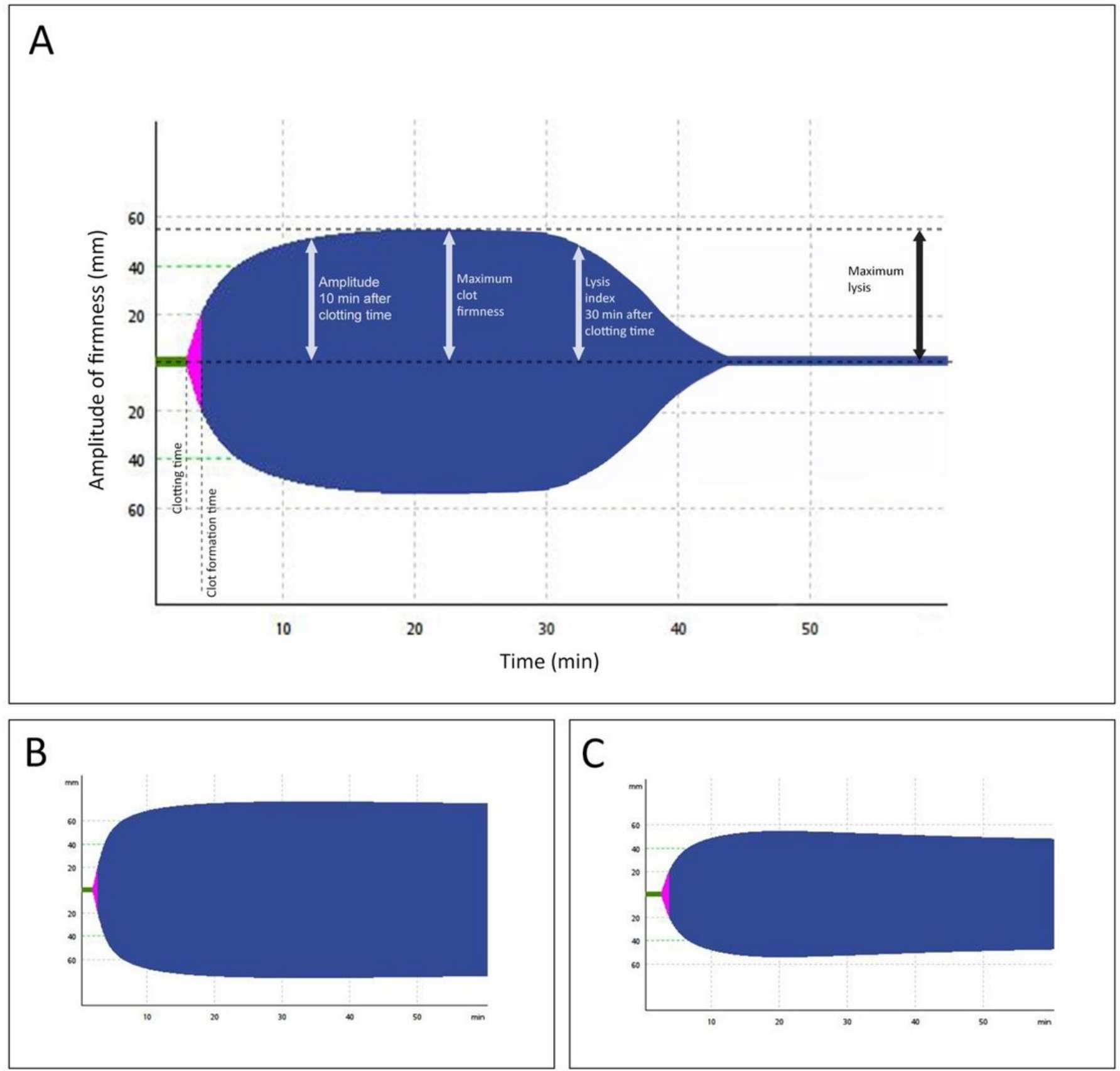

\section{Figure 1}

Panel A shows all measured values in ROTEM analysis, including clotting time (CT [s]), clot formation time (CFT [s]), maximum clot firmness (MCF [mm]) and maximum lysis (ML [\%(range)]). Panel B describes a fibrinolysis shutdown pattern (increased MCF, low ML) in a COVID-19 patient with a thromboembolic event; the clot amplitude remains unchanged until the end. Panel $\mathrm{C}$ shows a clot profile with reduced MCF and increased ML in a patient during the follow-up presentation. 

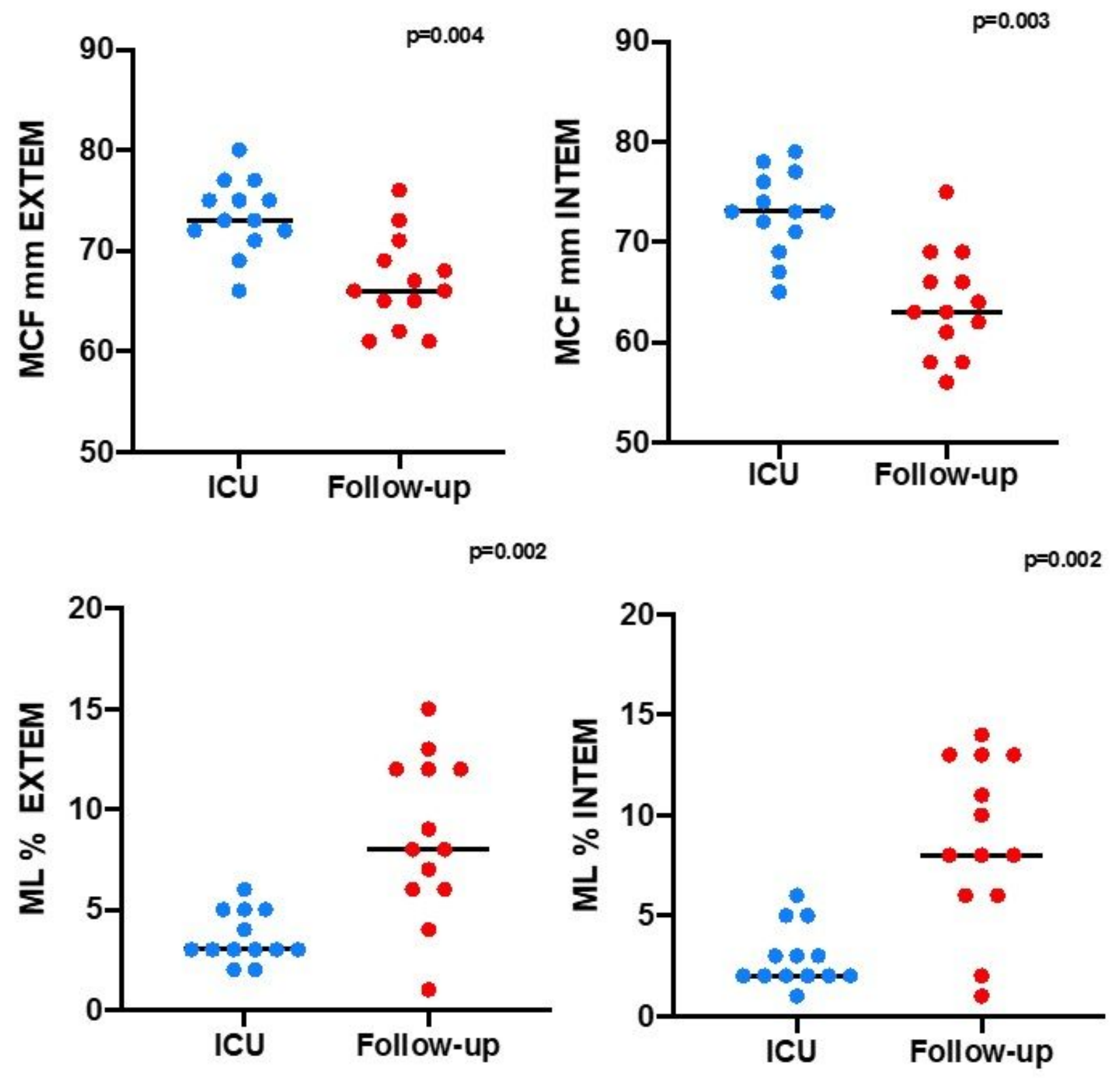

Figure 2

Comparison of coagulation parameters during ICU stay and follow-up visit $(n=13$, Wilcoxon signed rank test) . 

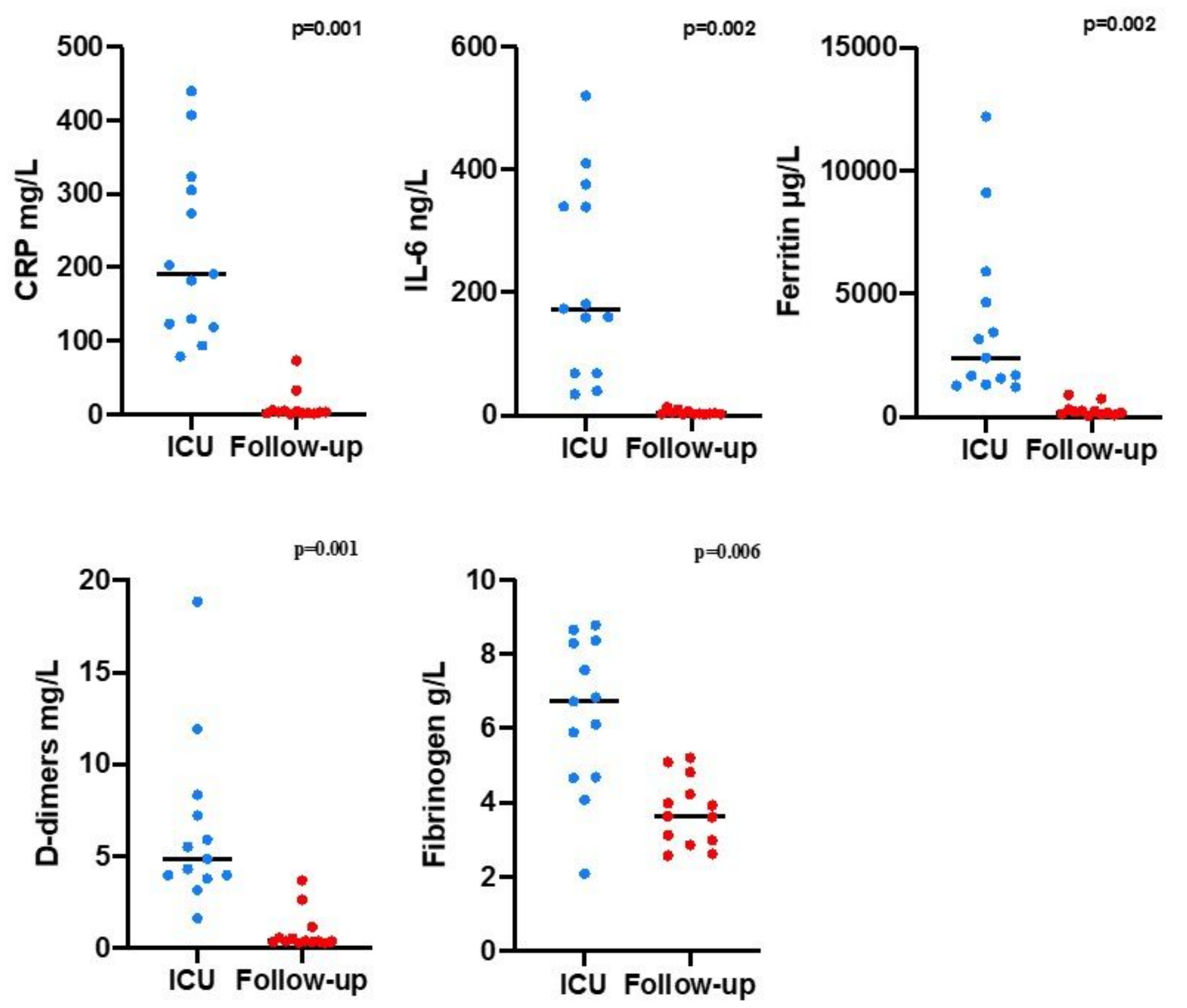

Figure 3

Comparison of inflammatory markers during ICU stay and follow-up visit $(n=13$, Wilcoxon signed rank test) .

\section{Supplementary Files}

This is a list of supplementary files associated with this preprint. Click to download.

- Graphicalabstract.jpg 